\title{
ChemComm
}

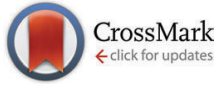

Cite this: Chem. Commun., 2016 52, 1759

DOI: $10.1039 /$ c6cc90030e

www.rsc.org/chemcomm

\section{Highlights from Faraday Discussion 182: Solid Oxide Electrolysis: Fuels and Feedstocks from Water and Air, York, UK, July 2015}

\author{
Elena Stefan* and Truls Norby
}

The rising importance of converting high peak electricity from renewables to fuels has urged field specialists to organize this Faraday Discussion on Solid Oxide Electrolysis. The topic is of essential interest in order to achieve a greater utilization of renewable energy and storage at higher densities.
The Faraday Discussion on Solid Oxide Electrolysis: Fuels and Feedstocks from Water and Air took place from 13-15 July 2015 in York, UK. The Ron Cooke Hub conference centre, in the Heslington East area of the University of York campus was the welcoming venue to approximately 60 electrochemists, solid state chemists, materials scientists, catalysis chemists, and chemical engineers brought together from around the world to discuss the fundamental aspects of solid oxide electrolysis (Fig. 1).

Faraday Discussions have a unique and interactive format, with all the delegates taking part in a "live peer-review" of the presented work. Papers submitted and reviewed a few months earlier are distributed to all participants before the meeting. During the meeting, the authors have only 5 minutes to present their work and each presentation is followed by extensive discussion for 20-25 minutes.

The conference began with a welcoming note from the conference chair, Professor John Irvine (University of St Andrews), who also represented the scientific committee comprising Professor Raymond Gorte (University of Pennsylvania), Professor Tatsumi Isihara (Kyushu University),

Department of Chemistry, University of Oslo, SMN, FERMIO, Gaustadalleen 21, NO-0349 Oslo, Norway. E-mail: elena.stefan@smn.uio.no

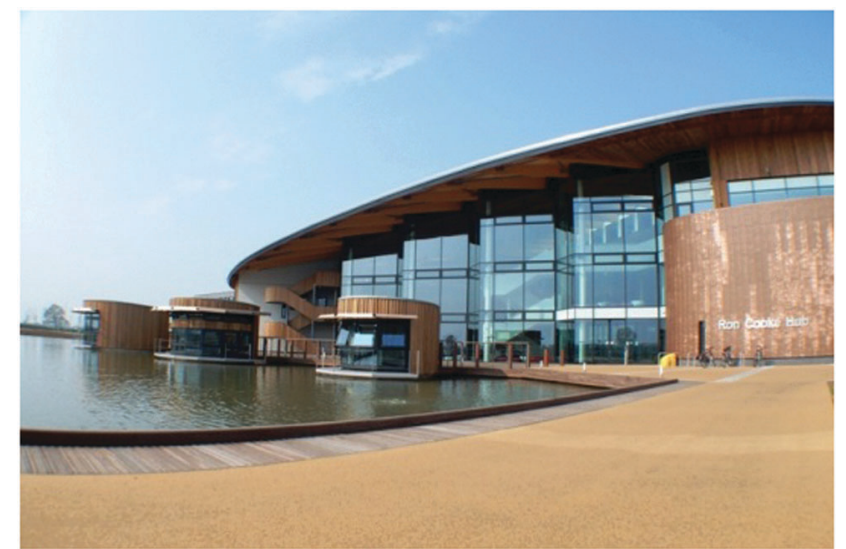

Fig. 1 The Ron Cooke Hub in the Heslington East area of the University of York campus.

Professor Mogens Mogensen (Technical University of Denmark), Professor Truls Norby (University of Oslo) and Professor John Varcoe (University of Surrey).

The introductory lecture was presented by John Hansen (Haldor Topsøe). The author gave insights into the efforts invested over the last four decades into renewable energy technology development, but also the remaining challenges and potential applications of the technology, from an industrial perspective (DOI: 10.1039/C5FD90071A). The following discussion focused on the current state and future directions in renewable energy technology, starting with exploiting the possibilities for the partial oxidation of hydrocarbons and ways to promote renewable energy.

\section{Day 1}

Session 1: Fundamental electrochemistry Session 1, chaired by Professor Raymond Gorte (University of Pennsylvania), had a dynamic start with the paper presented by Robert Kee (Colorado School of Mines) who described a model for the interpretation of the measured equilibrium conductivity and conductivity relaxation of ceramic materials with multiple mobile charged defects. The study focused on $\mathrm{BaZr}_{0.9} \mathrm{Y}_{0.1} \mathrm{O}_{3-\delta}$ (BZY10) with mixed conductivity of oxide ions, protons, and electrons. The developed model is based on a Nernst-Plank-Poisson formulation, suitable for a quantitative representation of conductivity relaxations for large changes in oxygen partial pressure 
(DOI: 10.1039/C5FD00012B). The subsequent discussion focused on how the conductivity and oxygen content of the material depend on the oxygen partial pressure. During the discussion it was noted that the outcome of the modelling indicates that the O-site polaron conductivity component (holes), under highly oxidizing conditions, is best described by a small polaron hopping mechanism rather than delocalized band conduction. Aspects of the certainty/uncertainty of the applied model, assumptions and the experimental conditions applied were also assessed (DOI: 10.1039/C5FD90073E).

The next paper, by Christopher Graves and co-workers, focused on the performance of a variety of electrodes (composites of nickel and yttria/scandia stabilized zirconia (Ni/SZ), Gd doped $\mathrm{CeO}_{2}$ (CGO), and CGO nanoparticles coating Nb-doped $\mathrm{SrTiO}_{3}$ backbones (CGOn/STN)) in $\mathrm{H}_{2} / \mathrm{H}_{2} \mathrm{O}$ and $\mathrm{CO} / \mathrm{CO}_{2}$ reactions, in $2 \mathrm{D}$ model and $3 \mathrm{D}$ porous geometries. The ratio of the electrode polarisation resistance $R_{\mathrm{p}}$ in $\mathrm{CO} / \mathrm{CO}_{2} v s$. $\mathrm{H}_{2} / \mathrm{H}_{2} \mathrm{O}$ was found to decrease from 33 to 2 , for model and porous $\mathrm{Ni} / \mathrm{SZ}$ electrodes. The improved performance of the porous electrodes originates in the extended 3-phase boundaries (3PBs) and the lower concentration of impurities at the 3PBs in the porous electrode. Ni/SZ showed higher activity for $\mathrm{H}_{2} / \mathrm{H}_{2} \mathrm{O}$ reactions than $\mathrm{CO} /$ $\mathrm{CO}_{2}$ reactions, with the $\mathrm{Ni} / \mathrm{SZ}$ interface being more active for oxidation than reduction. The CGOn/STN model electrodes showed the opposite behaviour, with higher activity for $\mathrm{CO} / \mathrm{CO}_{2}$ reactions and higher activity for reduction (DOI: 10.1039/ C5FD00048C). The following discussion addressed the importance of the electrode microstructure and catalytic activity for measurements in $\mathrm{H}_{2} / \mathrm{H}_{2} \mathrm{O}$ and $\mathrm{CO} / \mathrm{CO}_{2}$ reactions. The purpose of the model electrodes was to remove the microstructure effects and evaluate the electrocatalytic activity. It was noted that this approach was successful for the Ni/YSZ electrodes, while the model electrodes with CGO nanoparticles had a more complicated microstructure. Followup questions debated the ratio of the electrode polarisation defined for the model and porous electrodes, the influence of the impurities and the rate limiting processes, which could be very different in high temperature systems (DOI: 10. 1039/C5FD90073E).
In the following paper, Denis Cumming (University of Sheffield) and co-workers described the development of a modified commercial Diffuse Reflectance Infrared Fourier Transform Spectroscopy (DRIFTS) unit for the study of solid oxide cells (SOCs) under operating conditions. The set-up was successfully built and used to analyse the surface and the gas species under both fuel cell and electrolysis operating conditions (DOI: 10.1039/C5FD00030K). Questions and queries from the audience were related to the practical challenges and how the experimental conditions influence in situ DRIFTS analysis. The technique is very sensitive to contaminants and other parameters such as: signal to noise ratio, beam penetration, and sample history/ cleaning cycles. The experimental conditions also have an influence on the results, e.g. the humidity of the gas, as $\mathrm{H}_{2} \mathrm{O}$ bands overlap with carbonate bands. Also the thickness of the electrodes is directly related to the depth of penetration of the IR beam and is significant in monitoring the electrochemically active region.

The next paper, by Steven McIntosh et al. (Lehigh University), investigated the link between the oxygen exchange rate and the bulk oxygen anion diffusivity in Ruddlesden-Popper phases, focusing in their study on $\mathrm{LaSrCo}_{0.5} \mathrm{Fe}_{0.5} \mathrm{O}_{4-\delta}(n=1)$ (RPn1), $\mathrm{La}_{0.3} \mathrm{Sr}_{2.7} \mathrm{CoFeO}_{7-\delta}(n=2)(\mathrm{RP} n 2)$ and $\mathrm{LaSr}_{3} \mathrm{Co}_{1.5} \mathrm{Fe}_{1.5} \mathrm{O}_{10-\delta}(n=3)(\mathrm{RP} n 3)$ mixed ionic-electronic conducting (MIEC) materials. They used in situ neutron diffraction and pulsed isotopic surface exchange to examine bulk ion mobility and surface oxygen exchange rates of these phases. Finally, X-ray photoelectron spectroscopy (XPS) or high sensitivity low energy ion scattering (HS-LEIS) was employed for the assessment of the surface composition. The authors found that even for very similar and heavily Sr-enriched surfaces, the oxygen surface exchange rate differed by more than one order of magnitude between the three investigated phases, with RPn2 > RPn3 > RPn1. The isotopic pulse experiments showed that the material exchanges oxygen from the first $\sim 200 \mathrm{~nm}$. Since the Sr-enriched surface is only $\sim 20 \mathrm{~nm}$, the "bulk" transport rates contribute significantly to the measured surface exchange rates (DOI: 10.1039/C5FD00014A).
The presentation was followed by a detailed discussion on the importance of the surface composition for the oxygen exchange rate and most of the comments were related to the Sr-enriched surface. It is possible that $\mathrm{Sr}$ enrichment on the surface determines the increase of oxygen vacancies on the surface and makes it more active. The possibility of a subsurface enriched in Co was also mentioned. Other comments from the audience suggested the formation of a more active SrFe oxide phase on the surface. Further discussion built on methods to measure $k$ (surface oxygen exchange rate) and $D$ (bulk anion diffusivity) and the uncertainties in each case e.g. from conductivity relaxation measurements $v s$. isotope exchange measurements, the latter expectedly more reliable. It was also noted that HS-LEIS as a surface analysis method might not be very sensitive to defects present in small concentrations, but offers the advantage of determining composition information in the outermost surface of the material (DOI: 10.1039/C5FD90073E).

\section{Session 2: Materials development}

After the refreshments and afternoon tea in the poster room, session 2, chaired by Professor Mogens Mogensen, started with the paper presented by John Vohs et al. (University of Pennsylvania). The presented work focused on the investigation of $\mathrm{La}_{0.8} \mathrm{Sr}_{0.2} \mathrm{CrO}_{3-\delta}-\mathrm{YSZ}$ dual phase membranes for syngas production from methane. The influence of the surface modification on the obtained oxygen flux, in terms of the catalytic activity of the surface and its microstructure, was also investigated and discussed. The obtained results showed that significant improvements in the oxygen fluxes were obtained when the surface resistance was decreased by the addition of catalysts such as $\mathrm{CeO}_{2}$ and $\mathrm{CeO}_{2} / \mathrm{Pt}$ in the MIEC composite LSCr-YSZ membranes (Fig. 2) (DOI: 10. 1039/C5FD00007F).

Tae Ho Shin (University of St Andrews) presented the next paper which studied the performance of a new material, PrBaM$\mathrm{n}_{2} \mathrm{O}_{5+\delta}$ (PBMO5) as an active cathode for $\mathrm{CO}_{2}$ electrolysis. The material showed high performance at elevated temperatures (750-850 ${ }^{\circ} \mathrm{C}$ ). The material is obtained under reducing conditions from $\operatorname{Pr}_{0.5} \mathrm{Ba}_{0.5} \mathrm{O}_{3-\delta}$ (PBMO3), as a double perovskite with 

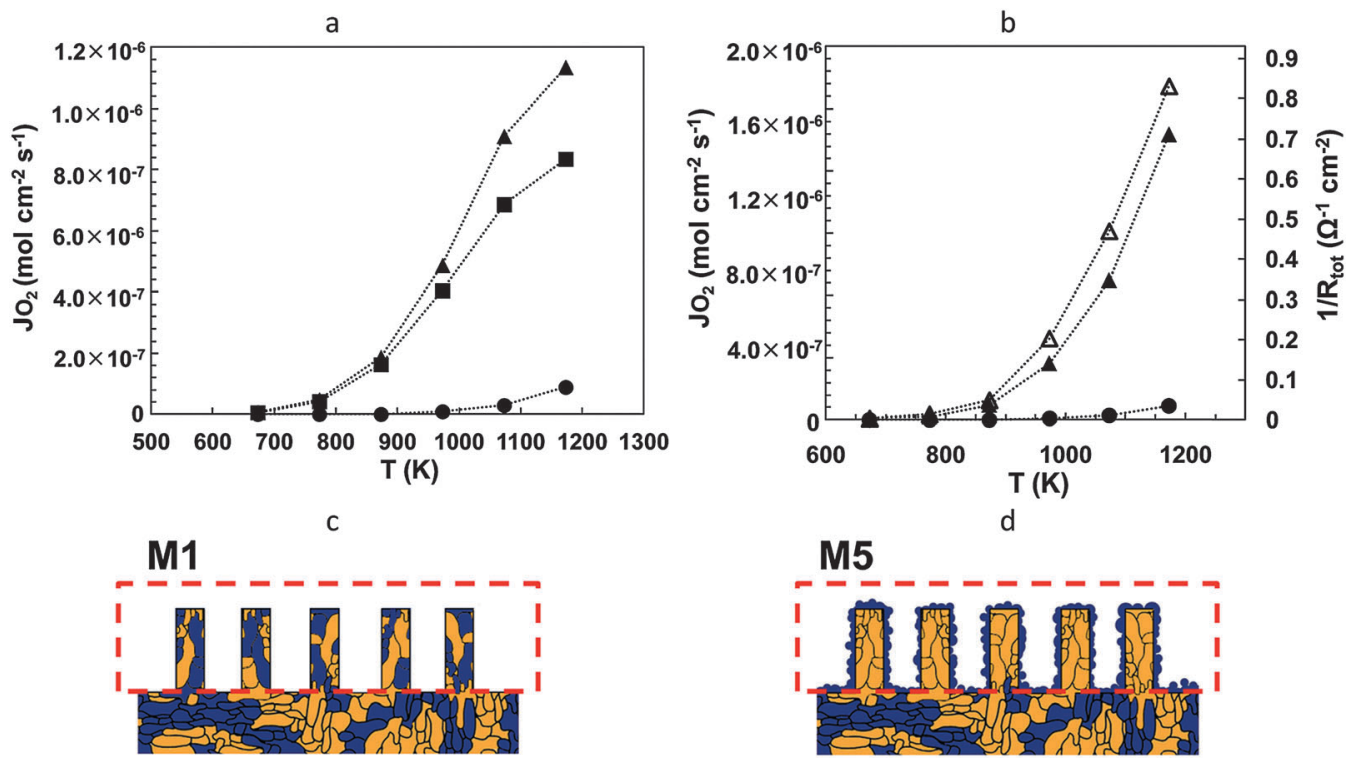

Fig. 2 Temperature dependencies of the oxygen permeation flux for LSCr-YSZ membranes with a LSCr-YSZ composite porous layer and various catalysts: (a) circle - unmodified membrane, square - addition of $\mathrm{CeO}_{2}$, and triangle - addition of $\mathrm{CeO}_{2}$ and Pt; (b) circle - unmodified membrane, full triangle - addition of $\mathrm{LSCr}$, and empty triangle - addition of $\mathrm{LSCr}$ and Pt. (c and d) Schematically represented surface microstructures of composite MIEC membranes, for oxygen flux measurements. The ionic conductor is given in yellow and the electronically conducting phase in blue (Reproduced from DOI: $10.1039 / C 5 F D 00007 F$ with permission from the Royal Society of Chemistry).

oxygen deficiency and A-site ordering. Upon oxidation at $800{ }^{\circ} \mathrm{C}, \operatorname{PrBaMn}_{2} \mathrm{O}_{6-\delta}(\mathrm{PBMO6})$ is formed. In the $\mathrm{O} 5$ phase fast oxygen transport is enhanced by the formation and ordering of oxygen vacancies, resulting in Pr layers without oxygen ions (Fig. 3). The structural change upon oxidation/reduction between $\mathrm{O} 5$ and $\mathrm{O} 6$ is found to be reversible, using thermogravimetric analysis. Solid oxide electrolysis cell/Solid oxide fuel cell (SOEC/SOFC) tests showed slow open-circuit voltage (OCV) recovery kinetics and slow
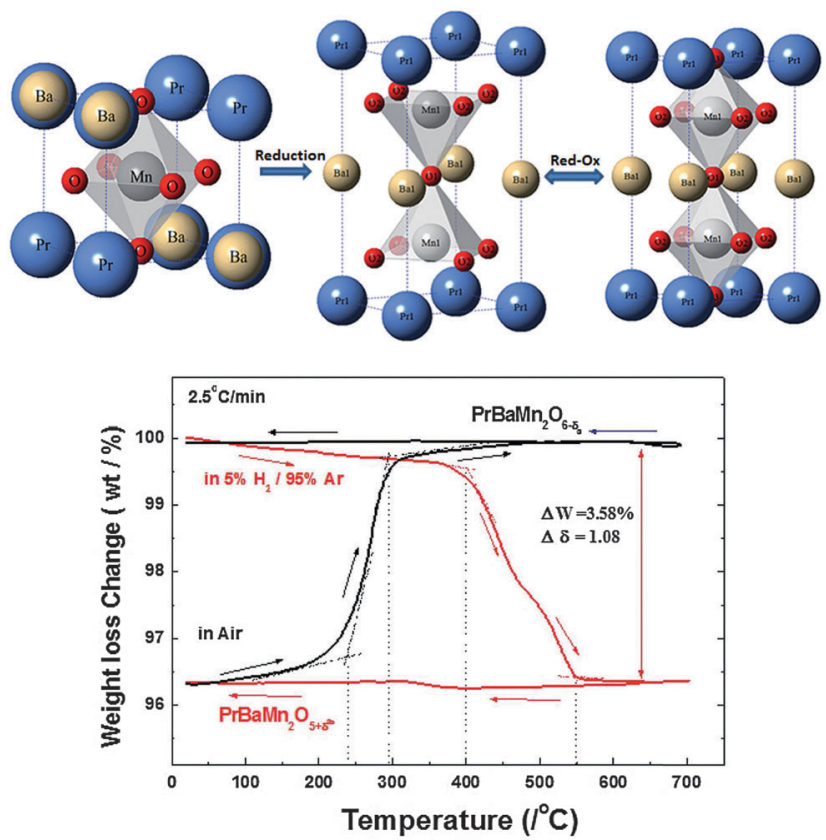

Fig. 3 PBMO3 crystal structure transformation upon reduction to PBMO5 and the reversible transformation of PBMO5 to PBMO6 upon oxidation. Thermogravimetric analysis confirms the reversible uptake/removal of oxygen from the structure (Reproduced from DOI: 10.1039/ C5FD00025D with permission from the Royal Society of Chemistry). surface kinetics for $\mathrm{CO}_{2}$ diffusion, explained in the paper by a possible temporary carbon deposition via the Boudouard reaction or a slow response of PBMO5 to the surface adsorption/desorption of $\mathrm{CO} / \mathrm{CO}_{2}$ species (DOI: 10.1039/C5FD00025D).

Next, Albert Tarancón (Catalonia Institute for Energy Research) investigated composite electrodes for steam $/ \mathrm{CO}_{2}$ co-electrolysis cells. The presence of a metallic phase in the electrode requires a continuous reducing gas flow to maintain the integrity of the electrodes. The use of full-ceramic symmetrical cells, with $\mathrm{La}_{0.75} \mathrm{Sr}_{0.25} \mathrm{Cr}_{0.5} \mathrm{Mn}_{0.5} \mathrm{O}_{3-\delta}$ (LSCM) as the electrode material and scandium and ytterbium stabilized zirconia (YbScSZ), as the electrolyte showed good electrochemical performance in the co-electrolysis mode. Despite the good results obtained for the co-electrolysis operation of the symmetrical cells, significant degradation by delamination was observed for the galvanostatic operation (DOI: 10 . 1039/C5FD00018A).

All three presentations stimulated active discussions on the materials development for electrolysis cells. The work presented on LSCr-YSZ dual phase membranes raised questions about a possible discontinuity in the ionic and electronic conductivity and the existence of double layers between 
the grains of the two phases. The comments from the audience and authors lead to the conclusion that optimized microstructures can overcome these issues. The percolation of each phase in the membrane would avoid any discontinuity in the conductivity and the big grains give a mixture of bulk contributions rather than double layer contributions. Also the chemical stability of the membranes was discussed and it was mentioned that at high temperatures (1400-1500 ${ }^{\circ} \mathrm{C}$ ) a reaction may occur at the interface between LSCr and YSZ, but at operating temperatures this problem would not be encountered.

The questions raised by the investigation of the new material $\operatorname{PrBaMn}_{2} \mathrm{O}_{5+\delta}$ as an active cathode for $\mathrm{CO}_{2}$ electrolysis were also related to the material stability, this time to coking and redox reversibility. There was also a considerable discussion on whether carbon deposition in PBMO5 would cause the observed increase in OCV. Another possible explanation may very well be the redox cycling between $\mathrm{O5}$ and 06. A number of methods for establishing or ruling out carbon deposition in an electrode were mentioned, starting with a comparison between testing conditions and the thermodynamic Boudouard threshold, calculating the possible carbon formation from the change in OCV, analysis of the exhaust gas, and testing in different compositions of $\mathrm{CO} / \mathrm{CO}_{2}$ with a higher $\mathrm{CO}$ fraction (DOI: 10.1039/C5FD90074C).

The discussion of the last paper on LSCM/YbScSZ/LSCM was directed towards the catalytic activity of the LSCM, its conductivity and performance in reducing conditions, and the cause of the degradation by delamination. It was noted that LSCM requires heating and maybe appropriate catalysts to get good performance. Pure LSCM was used as an electrode and sintered onto an electrode at $1200{ }^{\circ} \mathrm{C}$, with an anchor layer of CGO. It was suggested by other specialists in the field that a composite LSCM-electrolyte may result in a more robust structure, stable to delamination (DOI: 10.1039/C5FD90074C).

The second session was followed by a Lightning Session of 6 flash presentations selected by the organizers to highlight the most outstanding poster contributions. The flash presentations introduced the poster session and the following reception.

\section{Day 2}

\section{Session 1: Fundamental electrochemistry}

The second day started with the morning session, chaired by Professor Raymond Gorte (University of Pennsylvania). The first paper presented by Rotraut Merkle (Max Plank Institute) described the defect chemistry of $\mathrm{Ba}_{0.5} \mathrm{Sr}_{0.5} \mathrm{Fe}_{0.8} \mathrm{Zn}_{0.2} \mathrm{O}_{3-\delta}$ (BSFZ) as a $\mathrm{H}^{+}$-SOFC cathode material, using thermogravimetric studies. Materials with mixed ionic electronic conductivity give high cathode performances because of increased triple phase boundary surfaces. In particular, $\mathrm{H}^{+}$-SOFC cathodes require high p-type (hole) and proton conductivity. BSFZ has mixed hole, oxygen vacancy and proton conductivity. For this material the authors investigated the proton uptake and changes in the defect chemical behaviour of the material in different $p_{\mathrm{O}_{2}}$ conditions. The thermogravimetric investigation showed that BSFZ incorporates a nonnegligible number of protons, but less than barium zirconate and cerate electrolyte materials. Incorporation of protons in the material occurs differently depending on $p_{\mathrm{O}_{2}}$ : at low $p_{\mathrm{O}_{2}}$ the main reaction is hydration, when the oxygen vacancies are filled by dissociative adsorption of water. At high $p_{\mathrm{O}_{2}}$ the main reaction is hydrogenation, i.e., the presence of oxygen vacancies is not mandatory for proton uptake. The reactions are specified below (DOI: 10 . 1039/C5FD00013K):

$$
\frac{1}{2} \mathrm{O}_{2}+\mathrm{V}_{\mathrm{O}}^{\bullet \bullet}=\mathrm{O}_{\mathrm{O}}^{\times}+2 \mathrm{~h}^{\bullet} \quad K_{\mathrm{O}}=\frac{\left[\mathrm{O}_{\mathrm{O}}^{\times}\right]\left[\mathrm{h}^{\bullet}\right]^{2}}{p_{\mathrm{O}_{2}}^{1 / 2}\left[\mathrm{~V}_{\mathrm{O}}^{\bullet \bullet}\right]}
$$

$$
\begin{gathered}
\mathrm{H}_{2} \mathrm{O}+\mathrm{V}_{\mathrm{O}}^{\bullet \bullet}+\mathrm{O}_{\mathrm{O}}^{\times}=2 \mathrm{OH}_{\mathrm{O}}^{\bullet} \\
K_{\mathrm{W}}=\frac{\left[\mathrm{OH}_{\mathrm{O}}^{\bullet}\right]^{2}}{p_{\mathrm{H}_{2} \mathrm{O}}\left[\mathrm{O}_{\mathrm{O}}^{\times}\right]\left[\mathrm{V}_{\mathrm{O}}^{\bullet \bullet}\right.} \\
\mathrm{H}_{2} \mathrm{O}+2 \mathrm{O}_{\mathrm{O}}^{\times}+2 \mathrm{~h}^{\bullet}=2 \mathrm{OH}_{\mathrm{O}}^{\bullet}+\frac{1}{2} \mathrm{O}_{2} \\
K_{\mathrm{W} / \mathrm{O}}=\frac{p_{\mathrm{O}_{2}}^{1 / 2}\left[\mathrm{OH}_{\mathrm{O}}^{\bullet}\right]^{2}}{p_{\mathrm{H}_{2} \mathrm{O}}\left[\mathrm{O}_{\mathrm{O}}^{\times}\right]^{2}\left[\mathrm{~h}^{\bullet}\right]^{2}}
\end{gathered}
$$

Eqn (1) is the oxidation reaction, where oxygen vacancies are filled by oxygen from the gas phase, with the formation of holes, eqn (2) shows the hydration reaction and eqn (3) describes the hydrogenation reaction. The subsequent discussion offered an interesting insight from reviewers on the hydration and hydrogenation reactions as defined in the paper. The term "hydrogenation" here describes the uptake of hydrogen from water, without exposure to hydrogen. In comparison with the term used in organic chemistry (combination with molecular hydrogen), the important aspect is that eqn (3) describes an increase in the sample's proton concentration. It was established that eqn (3) may also be regarded as a two-step reaction (eqn (2), followed by eqn (1)) instead of one step reaction, where the water and oxygen are competing for vacancies (DOI: 10.1039/ C5FD90073E).

The next paper, presented by Helena Téllez (wpi-I2CNER), addressed the topic of the surface and near-surface chemical composition for $\mathrm{LnBaCo}_{2} \mathrm{O}_{5-\delta}$ electroceramic materials. The matter is of significant interest since these materials have good performance as air electrodes in solid oxide fuel cells and electrolyzers. However, they also show a high tendency for surface and sub-surface restructuring due to the segregation of the divalent alkaline-earth cation. The surface of these materials was analysed at the atomic scale at the gas-electrode interface, in order to link the surface composition with the surface exchange kinetics. Thus, extremely surface sensitive techniques such as lowenergy ion scattering (LEIS) and time-offlight secondary ion mass spectrometry (ToF-SIMS) were applied to study the MIEC materials. The double perovskite $\mathrm{GdBaCo}_{2} \mathrm{O}_{5+\delta}$ (GBCO) showed rapid segregation of the divalent $\mathrm{Ba}$ cation to the surface to form a $\mathrm{BaO}$ terminated layer at relatively low temperatures and over short periods of time (e.g. 15 minutes at $400{ }^{\circ} \mathrm{C}$ ). The segregation of Ba would be expected to passivate the surface by decreasing the electrocatalytically-active surface (i.e. $\mathrm{CoO}_{2}$-terminated surface), yet the obtained surface exchange coefficients seemed less sensitive to the surface composition than anticipated (DOI: 10.1039/ C5FD00027K).

The lack of correlation between the surface exchange and the surface composition generated an interesting discussion on the factors that influence the surface 
exchange rate. It was noted that this trend is consistent with a paper discussed earlier (DOI: 10.1039/C5FD00014A), where the same segregation of the alkaline A-site cation was observed with a lack of correlation between the surface composition and the surface exchange rate. It was observed that there is a link between the surface exchange rate and the bulk ionic transport and it was stated that the subsurface may be a factor in determining the activity. Even though the materials are characterized by the fast kinetics of the surface segregation at temperatures as low as $400{ }^{\circ} \mathrm{C}$, it may be possible that point defects at the surface play a key role (DOI: 10.1039/C5FD90073E). ${ }^{1}$ The complete discussion may be found in the discussion paper.

The last paper in the morning session was presented by Viola Birss (University of Calgary), on reversible solid oxide fuel cells (RSOFCs). $\mathrm{La}_{1-x} \mathrm{Sr}_{x} \mathrm{Fe}_{1-y} \mathrm{Cr}_{y} \mathrm{O}_{3-\delta}$ and $\mathrm{La}_{1-x} \mathrm{Ca}_{x} \mathrm{Fe}_{1-y} \mathrm{Cr}_{y} \mathrm{O}_{3-\delta}$ mixed ionic electronic conducting perovskite electrodes were tested as both oxygen and fuel electrodes for RSOFCs. The electrochemical performance of $\mathrm{La}_{0.3} \mathrm{Sr}_{0.7} \mathrm{Fe}_{0.7} \mathrm{Cr}_{0.3} \mathrm{O}_{3-\delta}$ (LSFCr-3) was presented in detail and it showed very good performance under different testing conditions. However, when analysing reactions occurring in the fuel cell or electrolysis mode, it was concluded that LSFCr-3 is a better catalyst for the oxygen evolution and $\mathrm{CO}_{2}$ reduction reactions than for oxygen reduction or CO oxidation. This indicates a better performance in the electrolysis $v s$. fuel cell mode (DOI: 10 . 1039/C5FD00029G). The subsequent discussion addressed the interpretation of the results regarding three electrode measurements. It was suggested that even though the geometrical arrangement is carefully considered, it doesn't mean that the measurements are necessarily correct. However, when compared with twoelectrode measurements and also considering the relatively thick electrode used, the three-electrode data are more likely to be trustworthy. The results reported as the concentration dependence of the current, under equilibrium and polarized conditions in air and $\mathrm{CO} / \mathrm{CO}_{2}$, were described as "apparent reaction orders" or "measured concentration dependencies". The interpretation of the impedance data was also in debate, especially the low frequency arc, which showed a large capacitance (up to $10 \mathrm{~F} \mathrm{~cm}^{-2}$ ). This contribution was attributed to the chemical capacitance of the MIEC material.

The refreshments and morning tea were a good opportunity for further interaction among delegates.

\section{Session 2: Materials development continued}

The second session of the day, chaired by Professor John Varcoe, was a continuation of the materials development session opened the previous day, with a wellselected distribution of papers.

Bilge Yildiz (Massachusetts Institute of Technology) and co-workers studied the Sr-segregation at the surface of $\mathrm{La}_{0.8} \mathrm{Sr}_{0.2} \mathrm{CoO}_{3}$ (LSC) $40 \mathrm{~nm}$ thin films and the improved stability of the material when coated with Ti (LSC-T), deposited from a chemical bath of $\mathrm{TiCl}_{4}$ solution. LSC-T showed decreased segregation of the blocking Sr-rich particles at the surface, ensuring a larger area of the material for the oxygen reduction reaction (Fig. 4). They found that the surface with a Ti content of
$10 \%$ (from XPS) improved the surface oxygen exchange up to 8 fold by hindering the segregation of the Sr-rich phases (DOI: 10.1039/C5FD00023H). These results stimulated a discussion about the effect of surface modification with the addition of Ti on the surface exchange kinetics. The catalytic properties change along with the cation chemistry. The Ti stabilizes the surface chemistry, but not the original chemistry of the perovskite; it is rather changing the cation chemistry to another more stable chemistry. It may very well form $\mathrm{SrTiO}_{3}$ on the surface, or Ti might dope the LSC forming a $(\mathrm{La}, \mathrm{Sr})(\mathrm{Co}, \mathrm{Ti}) \mathrm{O}_{3-\delta}$ perovskite on the surface (DOI: 10.1039/ C5FD90074C).

John Druce (Kyushu University) presented the next paper, which investigated the oxygen exchange, transport in MIEC ceramic composite electrodes and the inter-reaction or inter-diffusion of cations or impurities between the two phases. The solution often used for achieving electrodes with mixed conduction in SOECs and SOFCs is to use macroscopically mixed ceramic materials, mostly $\mathrm{Zr}_{1-x} \mathrm{Y}_{x} \mathrm{O}_{2-x / 2}$

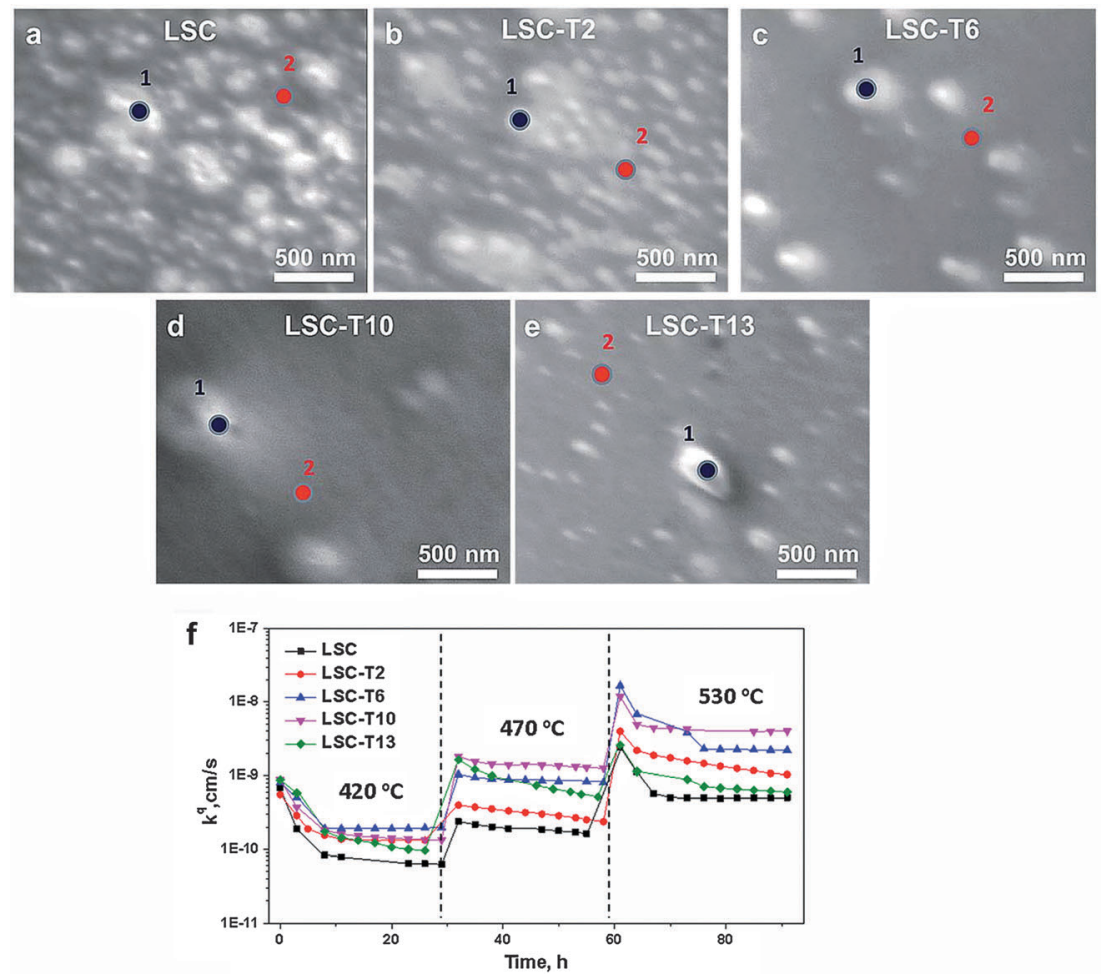

Fig. 4 SEM images of the surface morphology of LSC films without (a) and with Ti ((b) $2 \%$, (c) $6 \%$, (d) $10 \%$, (e) $16 \%$ ) on the surface. Ti was quantified as $\mathrm{Ti} /(\mathrm{La}+\mathrm{Sr}+\mathrm{Co}+\mathrm{Ti})$. (f) The oxygen surface exchange coefficient, $k^{q}$, over time at $420-530{ }^{\circ} \mathrm{C}$ (Reproduced from DOI: $10.1039 / \mathrm{C} 5$ FD00023H with permission from the Royal Society of Chemistry). 
(YSZ) and $\mathrm{Ce}_{1-x} \mathrm{Gd}_{x} \mathrm{O}_{2-x / 2}$, as ionic conductors and perovskites such as LSM or LSCF, as electronic conducting phases. The high temperatures required to sinter the materials can lead to reactions (e.g. in the case of LSM and YSZ, formation of $\mathrm{La}_{2} \mathrm{Zr}_{2} \mathrm{O}_{7}$ occurs, which blocks the oxygen transport). Surface sensitive techniques, namely ToFSIMS and LEIS, were used for the study of $50: 50$ (by weight) $\mathrm{Ce}_{0.9} \mathrm{Gd}_{0.1} \mathrm{O}_{1.95}$ (CGO) and $\mathrm{La}_{0.6} \mathrm{Sr}_{0.4} \mathrm{Co}_{0.2} \mathrm{Fe}_{0.8} \mathrm{O}_{3-\delta}$ (LSCF) composites. It was found that for lower temperatures $\left(500{ }^{\circ} \mathrm{C}\right){ }^{18} \mathrm{O}$ isotope fractions were homogenous across both phases at the surface of the composite. For each phase, at the same temperature it was observed that LSCF had a much higher ${ }^{18} \mathrm{O}$ fraction at the surface than CGO. Thus, in the composite, ${ }^{18} \mathrm{O}$ incorporation may occur predominantly in the LSCF and be transferred to some extent into the CGO phase. At higher temperatures $\left(700{ }^{\circ} \mathrm{C}\right)$, the ${ }^{18} \mathrm{O}$ isotopic fraction and apparent surface exchange coefficient was higher for CGO than for the LSCF in the composite. The authors proposed several mechanisms, as illustrated in Fig. 5, in light of the surface compositional analysis using LEIS and ToF-SIMS (DOI: 10. 1039/C5FD00028A).

The subsequent discussion reflected a positive reception of the results presented by John Druce and co-workers, regarding the high oxygen diffusion coefficients and surface exchange coefficients, attributed to

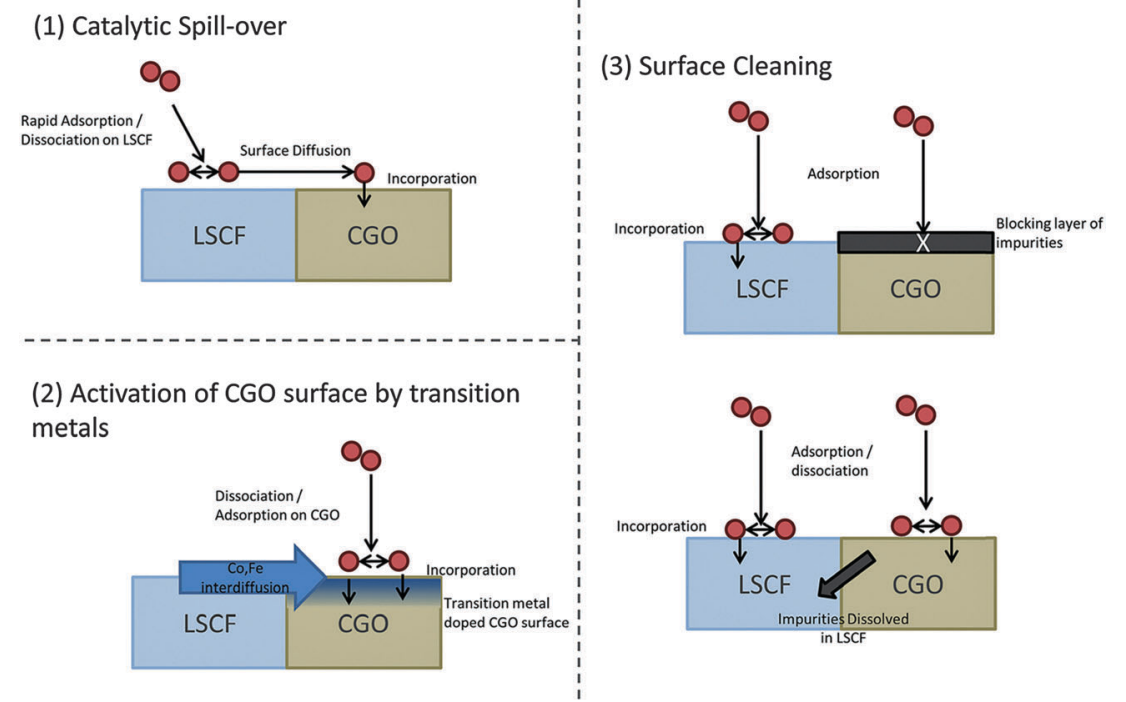

Fig. 5 Schematic of the possible mechanisms for the surface exchange enhancement of CGO grains in a LSCF-CGO composite (Reproduced from DOI: 10.1039/C5FD00028A with permission from the Royal Society of Chemistry).

the high purity of the samples and surfaces. It was also mentioned that removal of the impurities at grain boundaries in ceria can be done by the addition of scavengers, with a significant enhancement of the surface exchange rate (DOI: 10.1039/C5FD90074C).

The following paper presented by Chengsheng Ni (University of St Andrews), focused on the investigation of $\mathrm{CaMnO}_{3-\delta}$ (CM) and $\mathrm{CaMn}_{0.9} \mathrm{Nb}_{0.1} \mathrm{O}_{3-\delta}(\mathrm{CMN})$ as oxygen electrode materials for reversible solid oxide fuel cells (RSOFCs). CMN showed improved thermal stability in air and oxygen up to $900{ }^{\circ} \mathrm{C}$ with respect to the parent composition, CM. The materials were tested as oxygen electrodes at $700{ }^{\circ} \mathrm{C}$, in a three-electrode system. Both materials showed good performance, with a polarization resistance lower than $0.1 \Omega \mathrm{cm}^{2}$, but in different functioning modes: CM showed high performance as a cathode for SOFCs, bias (DOI: 10.1039/C5FD00026B).

The presentation stimulated an active discussion dominated by what would be the best possible configuration for applying electrodes in a three electrode system in order to minimise the errors, with the audience showing a lot of interest for the topic (DOI: 10.1039/C5FD90074C).

\section{Session 3: System studies}

The third session on "System studies" was chaired by Professor Tatsumi Ishihara and CMN as a anode for SOECs and under

(2) Activation of CGO surface by transition
(Kyushu University). The first paper of the session, presented by Joseph Hartvigsen (Ceramatec), described the interdependence between operating conditions (endothermic, thermoneutral or exothermic), power requirements and efficiency for solid oxide electrolysis cells, aiming at successful commercialization. The authors used a stack of SOEC hydrogen production with specified parameters (i.e. steam flow rates, operating voltage, and power density), and by combining them with estimated costs, they obtained a cost/performance model. The model was used for generating a performance map of a stack and the cost elements for a given set of performance parameters and operating conditions. The cost per unit hydrogen produced was also estimated for the pre-defined set of assumptions (DOI: 10.1039/C5FD00015G). The following discussion addressed the possibility of integrating other factors with a large impact on the lifetime of the system into the model, such as cell voltage or temperature or the possibility of modelling co-electrolysis in the same way as steam electrolysis (DOI: 10.1039/C5FD90075A).

The paper by Xinbing Chen (Shanghai Institute of Applied Physics, Chinese Academy of Sciences) and co-workers, investigated syngas production by high temperature steam $/ \mathrm{CO}_{2}$ co-electrolysis using commercially available SOECs. The tested SOECs were cathode supported cells with a Ni-YSZ cathode/YSZ electrolyte/GDC buffer layer/LSCF $\left(\mathrm{La}_{0.6} \mathrm{Sr}_{0.4} \mathrm{Co}_{0.2} \mathrm{Fe}_{0.8} \mathrm{O}_{3-\delta}\right)$ anode. It was found that the electrochemical performance of the high temperature (HT) steam $/ \mathrm{CO}_{2}$ co-electrolysis mode is close to that of HT steam electrolysis and higher than $\mathrm{HT} \mathrm{CO}_{2}$ electrolysis, with area specific resistances (ASRs) of $0.70-0.79 \Omega \mathrm{cm}^{2}$, $0.75 \Omega \mathrm{cm}^{2}$ and $1.06 \Omega \mathrm{cm}^{2}$, respectively. The ASR values are indicative of the important role of the water-gas shift reaction in the formation of $\mathrm{CO}$ during the $\mathrm{HT}$ steam $/ \mathrm{CO}_{2}$ electrolysis process (DOI: 10 . 1039/C5FD00017C). The subsequent discussion focused on the reported OCV values, in particular that the OCV increased at high $\mathrm{CO}_{2}$ conditions (80\%). In these tests the OCV value should not vary significantly with $\mathrm{CO}_{2}$ concentration, and the variation was probably caused by incorrect gas composition (DOI: 10.1039/ C5FD90075A). 
The last paper of the session, presented by Shanwen Tao (University of Strathclyde, University of Warwick), investigated the synthesis of ammonia electrochemically, from wet air (or $\mathrm{N}_{2}$ ) using $\mathrm{Sm}_{0.6} \mathrm{Ba}_{0.4^{-}}$ $\mathrm{Fe}_{0.8} \mathrm{Cu}_{0.2} \mathrm{O}_{3-\delta}$ as a catalyst. The authors reported the successful synthesis of ammonia at $400{ }^{\circ} \mathrm{C}$ under atmospheric pressure, in a single chamber reactor. The obtained rates for the production of $\mathrm{NH}_{3}$ were $9.19 \times 10^{-7} \mathrm{~mol} \mathrm{~s} \mathrm{~m}^{-1}$ and $1.53 \times 10^{-6} \mathrm{~mol} \mathrm{~s}^{-1} \mathrm{~m}^{-2}$. These values were relatively low for mass production (DOI: 10.1039/C5FD00033E). Questions and comments following the presentation pointed to the possible liabilities of the testing setup that could generate misleading results. The calculated ammonia equilibrium exiting the cells was admittedly three orders of magnitude lower than the measured value. Ammonia is detected through the neutralisation of sulfuric acid. Thus, the detection method (a standard commercial ammonia detector) needs to be backed up by a blank experiment where the input compressed air is passed through the setup chamber and sulfuric acid, without a cell inside (DOI: 10.1039/C5FD90075A).

\section{Session 4: Understanding durability}

The last session of the day, chaired by John Vohs (University of Pennsylvania) focused on durability studies for electrolyser cells. The first paper of the session, presented by Scott Barnett (Northwestern University), reported on the degradation of solid oxide cells, operated under reversing current. LSC-YSZ composite electrodes were tested in air at $800{ }^{\circ} \mathrm{C}$, under current densities between 0.5 to $1.5 \mathrm{~A} \mathrm{~cm}^{-2}$, with each step being measured for $150 \mathrm{~h}$. The obtained results were used for running more tests at several current densities $\left(0.6,0.8\right.$ and $\left.0.9 \mathrm{~A} \mathrm{~cm}^{-2}\right)$ for $1000 \mathrm{~h}$. It was found that for higher current densities and over potentials the degradation rate increased rapidly, while under $0.5 \mathrm{~A} \mathrm{~cm}^{-2}$ and $0.6 \mathrm{~A} \mathrm{~cm}^{-2}$ the degradation rates were $1 \%$ and $3 \%$ after $1000 \mathrm{~h}$ for symmetric current cycles, with a period of $12 \mathrm{~h}$. The degradation resulted in the increase of the ohmic resistance and for higher current densities only the polarization resistance also increased. The degradation observed in the increased resistances was associated with microstructural and chemical changes in the electrode structure after cycling. It was observed using SEM-EDS that after cycling the number of LSM particles in the electrode increased and there was a reduction in the amount of LSM and YSZ at the electrode/electrolyte interface (Fig. 6), eventually leading to delamination and failure of the cell. The authors concluded that for lower current densities the degradation rate can be reduced below $1 \%$ per 1000 h (DOI: 10.1039/C5FD00020C).

The following discussion considered the reversibility and possible mechanisms for the observed degradation were identified as: (1) oxygen bubble formation in YSZ and (2) rupture in the perovskite electrode due to chemical expansion/contraction with varying $p_{\mathrm{O}_{2}}$. It was mentioned that these degradation mechanisms are probably general and will occur in most materials, under sufficiently extreme conditions. Even so, some materials may be more resistant, providing reduced or no degradation, for reasonable working conditions (DOI: 10. 1039/C5FD90075A).

The next paper introduced by Andreas Egger (Montanuniversitaet Leoben), focused on the study of $\mathrm{La}_{2} \mathrm{NiO}_{4+\delta}$ (LNO) as an oxygen electrode and CGO electrolyte for SOECs. Long-term tests under a constant current load of $-410 \mathrm{~mA}$ at
$800{ }^{\circ} \mathrm{C}$ were conducted with and without a Cr-source in the close vicinity of the cell. It was found that after more than $3000 \mathrm{~h}$ of functioning, the area specific resistance of the electrode increased by $350 \%$, from 0.22 to $1 \Omega \mathrm{cm}^{2}$. Post-test investigations did not reveal a significant amount of $\mathrm{Cr}$ in the electrode, but other contaminants were identified, such as $\mathrm{Si}$ and $\mathrm{Bi}$. They also found poor contact at the electrode/electrolyte interface (DOI: 10.1039/C5FD00021A).

The discussion followed the mechanism of the $\mathrm{Cr}$ deposition and the lack of $\mathrm{Cr}$ deposited under SOEC anode conditions. It was suggested that $\mathrm{Cr}$ deposition mechanisms may be suppressed on anodically polarised LNO. It was established that LNO is not a Cr-tolerant material, since Cr-deposition was detected under non-polarised conditions. An impurity source for $\mathrm{Bi}$ was identified to be the gold paste (DOI: 10.1039/C5FD90075A).

After a short break between the session and the dinner, the participants were invited to pre-dinner drinks. The highlights of the conference dinner were awarding the Poster Prize, sponsored by Cogent SCC, and the "Loving Cup Ceremony", using the traditional silver cup. The "Loving Cup Ceremony" was performed by the

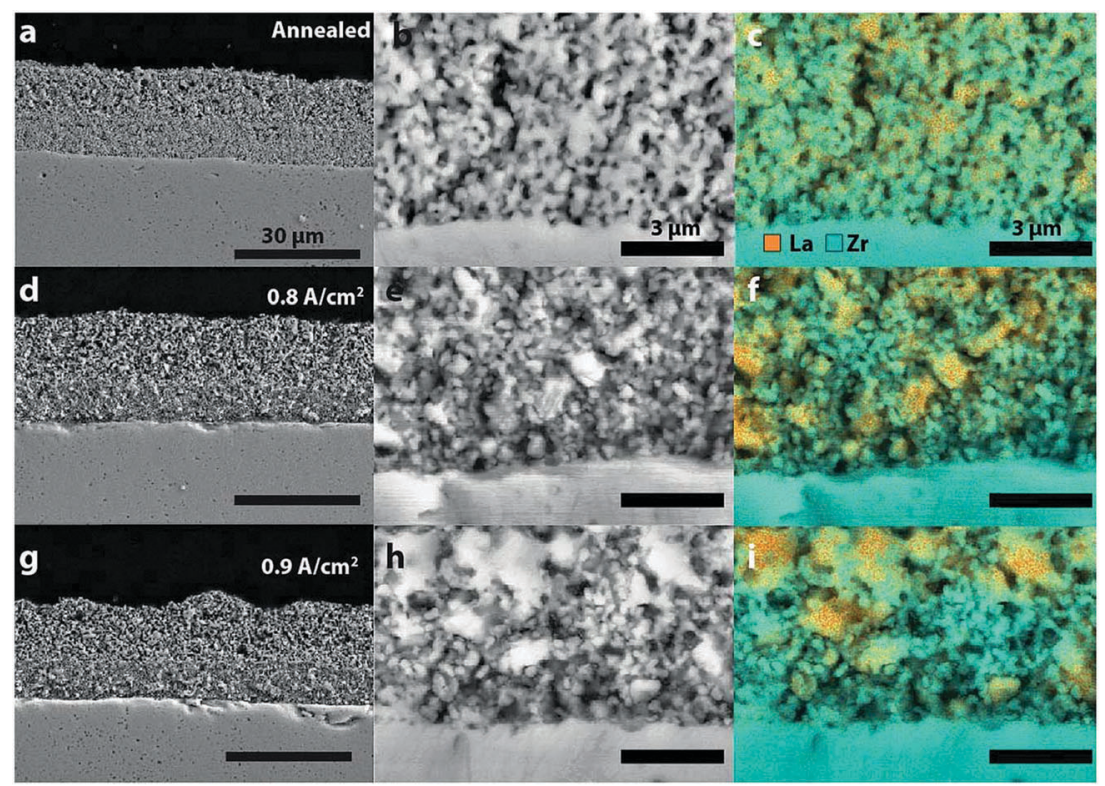

Fig. 6 Microstructural and chemical analysis, showing significant changes in the electrode structure by de-mixing of the composite LSM-YSZ electrode and depletion of material from the electrode/ electrolyte interface (Reproduced from DOI: 10.1039/C5FD00020C with permission from the Royal Society of Chemistry). 


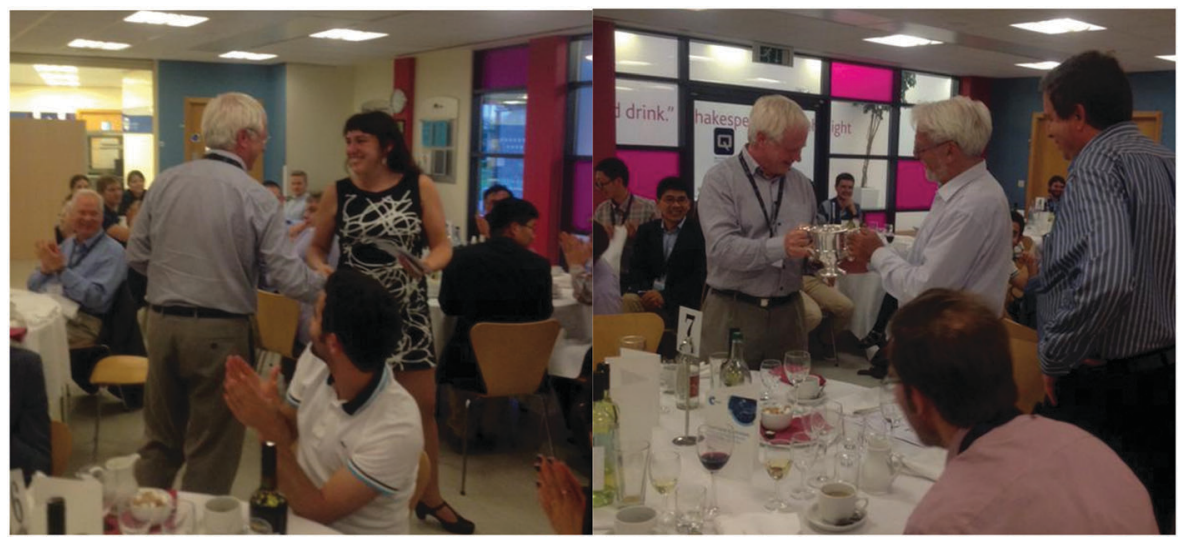

Fig. 7 Beatriz Molero-Sanchez wins the Poster Prize sponsored by Cogent SCC; the "Loving Cup Ceremony" (Images taken by Victoria Richards $(\mathbf{C}) 2015$ Royal Society of Chemistry).

Faraday Committee chair Professor John Irvine and Dr John Hansen (Fig. 7).

The session on durability studies was resumed the next day, chaired by Professor San Ping Jiang. The first paper, presented by Sune Ebbesen (DTU), focused on the durability studies of Ni-YSZ electrode supported Solid Oxide Cells (SOCs) operated both in the fuel cell mode and electrolysis mode at 750, 800 and $850{ }^{\circ} \mathrm{C}$, in $\mathrm{H}_{2} \mathrm{O} / \mathrm{H}_{2}$, $\mathrm{CO}_{2} / \mathrm{CO}$ and $\mathrm{H}_{2} \mathrm{O} / \mathrm{H}_{2} \mathrm{O} / \mathrm{CO}_{2} / \mathrm{CO}$ reactions. Polarisation tests ( $i-V$ curves) show that the reduction of $\mathrm{H}_{2} \mathrm{O}$ and $\mathrm{CO}_{2}$ is slower than the oxidation of $\mathrm{H}_{2}$ and $\mathrm{CO}$. The cells are reported to perform better in the FC-mode than in the EC-mode due to the exothermic reaction in FCs, and the endothermic reaction in EC. Both the ohmic resistance and electrode resistances are higher in EC in comparison to the FC mode (DOI: 10.1039/C5FD00032G). During the discussion it was noted that diffusion was so much more important in electrolysis than in the fuel cell mode. The effect of the diffusion was reflected by an increased diffusion resistance and increased conversion resistance, with the increase in total resistance being more affected by the change in conversion resistance. Further discussion debated the temperature dependence of the gas diffusion resistance as being mostly zero, while the surface diffusion resistance is thermally activated. These are two components that are in the same frequency range and might contribute to the low frequency arc here (DOI: 10.1039/C5FD90075A).

The next paper, presented by Marc Torrell (Catalonia Institute for Energy Research), reported on mesoporous nanocomposite materials for SOEC electrodes. NiO-CGO, with CGO infiltrated into NiO mesoporous scaffolds, was used as a fuel electrode and $\mathrm{Sm}_{0.5} \mathrm{Sr}_{0.5} \mathrm{CoO}_{3-\delta}$ (SSC) infiltrated with $\mathrm{Ce}_{0.8} \mathrm{Sm}_{0.2} \mathrm{O}_{1.9}$ (SDC), was used as an oxygen electrode. The performance of SOECs based on such electrodes was characterized in operating conditions by impedance spectroscopy and $i-V$ polarization curves. A maximum current density of $330 \mathrm{~mA} \mathrm{~cm}{ }^{-2}$ was obtained at $1.7 \mathrm{~V}$ and $850{ }^{\circ} \mathrm{C}$. The cells tested showed a high ohmic resistance to start with, and degraded relatively quickly by delamination of the oxygen electrode. The mesoporous structure of the electrodes did not alter very much after the tests, thus further optimization of the electrode adhesion to the electrolyte may lead to improved results (DOI: 10.1039/ C5FD00035A). The subsequent discussion focused on the microstructure optimization and better methodology for adding electrodes to the electrolyte. The authors stated that both the anode and the cathode materials for symmetric cells have already been tested for $1000 \mathrm{~h}$, with very encouraging results. The ASR in fact improved with the time of operation during the first $1000 \mathrm{~h}$. Other approaches for optimizing the microstructure were also suggested, e.g. changing the pore size of the mesoporous silica templates which may also facilitate measurements of the electrode surface area.

Another question referred to the structure of the fuel electrode: changing the scaffold from NiO to CGO. This approach was tested and CGO resulted in a more dense structure and the infiltration of $\mathrm{NiO}$ in the scaffold became more difficult (DOI: 10.1039/C5FD90075A).

The paper presented by San Ping Jiang (Curtin University) focused on the performance and stability of $\mathrm{La}_{0.8} \mathrm{Sr}_{0.2} \mathrm{MnO}_{3}$ (LSM) oxygen electrodes in the presence of $\mathrm{Fe}-\mathrm{Cr}$ metallic interconnections, while being tested under SOEC operating conditions, at $800{ }^{\circ} \mathrm{C}$. The results showed accelerated degradation of electrocatalytic activity and delamination of the LSM electrodes. $\mathrm{Cr}$ deposited in the bulk of LSM and at the interface of LSM/YSZ, both on the LSM inner surface and the YSZ interface. Formation of $\mathrm{Cr}$ oxides $(\mathrm{Cr}$, $\mathrm{CrO}_{0.87}, \mathrm{Cr}_{2} \mathrm{O}_{3}, \mathrm{Cr}_{2} \mathrm{O}_{5}$ ) and $\mathrm{SrCrO}_{4}$ was demonstrated using SIMS, GI-XRD, EDS and XPS analysis, instead of the $(\mathrm{Mn}, \mathrm{Cr})_{3} \mathrm{O}_{4}$ spinel phase that is usually formed in the LSM electrode under SOFC operating conditions. It was concluded that anodic polarisation promotes Sr segregation and depresses $\mathrm{Mn}$ segregation, leading to chromium oxides and $\mathrm{SrCrO}_{4}$ formation (DOI: 10.1039/C5FD00010F).

These results stimulated a discussion about the Sr enrichment and segregation as the main driving force for $\mathrm{Cr}$ deposition (as also stated in the paper) and solutions for diminishing the Sr segregation. When it was suggested to use A-site deficient LSM, which might suppress the $\mathrm{Sr}$ segregation, the authors mentioned that they have ongoing tests and the results will be available soon.

An interesting answer followed a question regarding the possibility of reversing $\mathrm{Cr}$ poisoning by oscillating between SOEC and SOFC modes. It was pointed 
out that the reverse of $\mathrm{Cr}$ deposition would be unlikely, as Cr deposits are thermodynamically stable. Plus, Cr deposition occurs in LSM electrodes also under SOFC operating conditions (DOI: 10. 1039/C5FD90076J).

The next paper, introduced by Minfang Han (Tsinghua University), investigated $\mathrm{Sm}_{0.5} \mathrm{Sr}_{0.5} \mathrm{CoO}_{3-\delta} \quad$ (SSC)-YSZ oxygen electrodes, prepared by the infiltration of SSC in a porous YSZ backbone. The electrode was tested both in SOFC and SOEC modes, with NiO-YSZ as the hydrogen electrode and a YSZ electrolyte. The results showed that SSC particles agglomerated and the delamination of the SSC-YSZ electrode from the electrolyte was caused by segregation of cobalt-enriched particles at the interface (DOI: 10.1039/C5FD00022J). The subsequent discussion followed possible causes of the observed delamination: $e . g$. the processing route of the backbone attachment to the electrolyte was described as warm isostatic pressing. However it was observed by EDS in the cross-section micrographs of the tested cells that the segregated phase is Co-rich and no $\mathrm{Sr}$ was detected. These observations justified raising the question of whether $\mathrm{Sr}$ zirconate was formed or not at the YSZ/SSC interface (DOI: 10.1039/ C5FD90076J).

The final paper was presented by Lan $\mathrm{Hu}$ (KTH Royal Institute of Technology), on the electrode kinetics of porous $\mathrm{NiO}$, used as an electrode for oxygen production in molten carbonate electrolysis cells (MCEC), at 600-650 ${ }^{\circ} \mathrm{C}$. Reaction orders of oxygen and carbon dioxide were determined from steady-state polarization data, for various gas compositions and temperatures. The results showed that partial pressure dependencies on the exchange current density are between 0.97 and 0.8 for oxygen $\left(600-650{ }^{\circ} \mathrm{C}\right)$. For $\mathrm{CO}_{2}$ there are two cases for the reaction order: positive

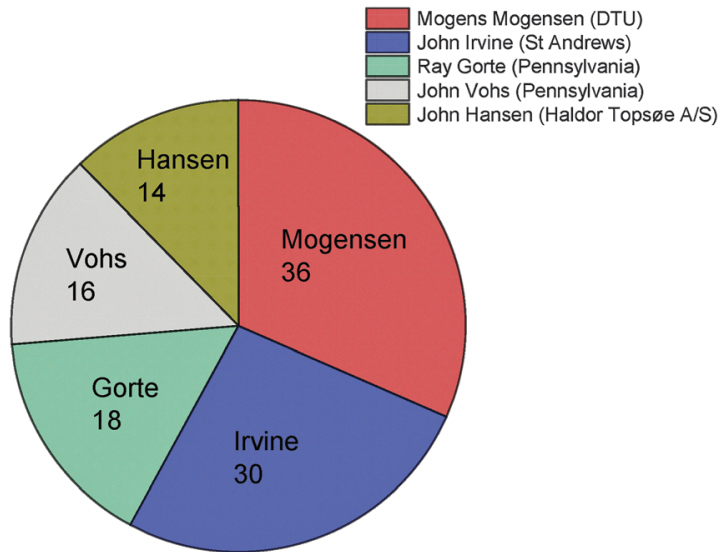

Fig. 8 Pie-chart showing the top five reviewers of the meeting.

values of 0.09-0.30 at low $\mathrm{CO}_{2}$ concentration; and a negative dependency ( -0.26 to 0.01 ) for high $\mathrm{CO}_{2}$ content. The activation energy for the NiO porous electrode for oxygen production was reported to be between 278-211 kJ mol ${ }^{-1}$ for increasing $\mathrm{O}_{2}$ content, and in the range of $124-229 \mathrm{~kJ} \mathrm{~mol}^{-1}$ for increasing $\mathrm{CO}_{2}$ content (DOI: 10.1039/ C5FD00011D). The following discussion established that the Au reference electrodes used in the testing setup were stable. For measuring overpotentials, potential was applied to simulate the electrolysis mode and the overpotentials were measured in potentiostatic steps. Further discussion built on other products that might form during MCEC operation, besides $\mathrm{H}_{2}$. CO forms from the water-gas shift reaction or it might form by $\mathrm{CO}_{2}$ electrolysis. It was also mentioned that Ni has a better wettability than $\mathrm{NiO}$ in molten carbonate (DOI: 10.1039/C5FD90076J).

The concluding remarks were delivered by Professor Guntae Kim (UNIST), who summarized what the speakers presented, the main comments and answers, and gave the opportunity to the speakers to answer again or to revise their answers (DOI: 10. 1039/C5FD90072G).
The concluding remarks were followed by well-deserved acknowledgements: Professor John Irvine acknowledged the delegates for coming, participating and asking questions and the RSC events team. He proposed the organization of another Faraday Discussions meeting on Solid State Electrochemistry. Victoria Richards (RSC events team) further thanked Professor Irvine and the organizing team from St Andrews for taking care of the organizational detail throughout the meeting. Victoria gave us a "winner" for the most comments and questions and a ranking of the top 5 reviewers, by number of questions (Fig. 8).

\section{Acknowledgements}

Financial support from the Research Council of Norway (RCN) through the ENERGIX program (Project No. 228819/ E20) is gratefully acknowledged.

\section{References}

1 J. A. Kilner, R. A. De Souza and I. C. Fullarton, Surface exchange of oxygen in mixed conducting perovskite oxides, Solid State Ionics, 1996, 86-88(Part 2), 703-709. 